\title{
Professional Emotional Education under the Deep Integration of University and Enterprise
}

\author{
Xiujuan Sun \\ Information Science and Technology, Taishan University \\ Taian, China
}

\begin{abstract}
In order to cultivate applied talents, China has been promoting the talent training model of school-enterprise cooperation in recent years. During execution of the mode, a series of problems arise. At present, the mode of schoolenterprise cooperation is still more focused on knowledge and skills. In terms of professional emotional education, both school and enterprise have not done enough, or even been lack of it. Under this kind of education mode, students only study mechanically without rich emotion, and encounter a lot of emotional resistance in learning. As a result, the teaching effect is not good, and the employment situation is worrying. Therefore, university and enterprise should deeply integrate in professional emotional education to help students establish positive and stable professional emotions, improve students' sense of professional pride, accomplishment, happiness and identity, and then promote the effective implementation of the teaching process and the sustainable development of the whole industry.
\end{abstract}

Keywords-professional emotional education; school-enterprise cooperation; deep integration; sustainable development

\section{INTRODUCTION}

Entering the university, students begin to learn professional knowledge and will soon face employment. But at present, the disconnection between education and employment often occurs in local colleges and universities. This will lead to students having no goals when they study and no confidence and interest when they look for jobs. In order to solve such problems, China has been implementing the school-enterprise cooperation education model to make up for the shortcomings of schools by virtue of the advantages of enterprises in the industry in recent years. From the results of the current schoolenterprise cooperation, students' professional skills have indeed been improved. But from the employment data of graduates in recent years, the employment situation is not ideal. Many students lack sense of belonging, accomplishment and pride in their majors and abandon relevant fields when they choose their first job. Others students choose the employment field of their majors, but their turnover rate is also high and employment persistence is insufficient.

The reason, students lack professional emotion. At present, the mode of school-enterprise cooperation still focuses more on knowledge and skills, but not enough on professional emotional education. However, students' professional learning time is limited. Once professional emotion is absent, negative emotion gradually accumulates, students will soon abandon their majors, and the situation will be difficult to reverse. Therefore, the problem of professional emotional education should be paid attention to as soon as possible, and professional emotional education should start as soon as possible.

\section{DEFINITION OF PROFESSIONAL EMOTION}

Emotion is a part of the whole attitude. It is in consistent with the introverted feeling and intention of the attitude, and a relatively complex and stable physiological evaluation and experience of attitude in physiology. Students' professional emotion refers to their inner experience whether their majors can meet their psychological and social needs. Through the cultivation of professional emotions, students can acquire a strong cognitive tendency to what they have learned in emotion, and then actively implement and internalize what they have learned in action [1]. Professional emotion has sustainable power, which can help students to obtain professional identity and happiness, and then ensure the employment persistence and promote the sustainable development of the industry.

Next, the paper will analyze the main reasons of the professional emotion loss, and then propose the strategy of deep integration of school and enterprise in professional emotional education.

\section{THE CAUSE OF PROFESSIONAL EMOTION LOSS}

Learning is a long process, and the professional emotion loss is also gradually accumulated. Taking computer major as an example, the paper will analyze how professional emotional problems arise from the following aspects.

\section{A. The anxiety about professional learning}

Before entering the university, students mainly study basic courses having continuity. For example, math is taught from elementary school to middle school, but the difficulty is gradually increasing. In college, apart from some public courses, students mainly learn the professional knowledge and skills of their chosen majors. These knowledge and skills are largely not taught before college, and students will be exposed to a completely new teaching system. According to the survey, students generally lack professional cognition, do not know what the major is and what the employment direction is when choosing their majors. Therefore, students tend to be anxious before learning. This anxiety will cause students to have no goal and direction in their later learning, and do not know what the application value of professional learning is.

2018 Taishan University young teachers fund project (QN-01-2018-07) 


\section{B. The accumulation of frustration in learning process}

Before professional learning, students didn't know about the internal structure of computer and programming focused more on theory than practical ability. Logical thinking abilities had not been well exercised, so they lacked systematization and standard. Therefore, when students learn programming courses such as $\mathrm{C}$ language, they will feel strange and easily make mistakes in details such as colons and indents. When designing programs, they tend to produce confusion of logical thinking, and fear to touch programs with a little more content. Solving such problems requires a process of constant practice and revision. During the process, students are prone to frustration. If handling the frustration is not proper, the frustration will gradually accumulate with the learning progress, and even cause students to be tired of learning, resist and give up. Professional courses are related, so the failure of one course often affects the learning of other courses. In particular, the failure of basic professional courses is likely to affect the overall learning situation.

\section{Fear of large projects and lack of team spirit}

Programming courses are designed to solve practical problems, and solving an actual meaning problem often need a large-scale programming project. Therefore, after the teaching of programming courses, teachers will instruct students to complete some simulated projects. The scale of these projects is larger than the usual class cases. The purpose of these projects is to train students' systematization, logical thinking abilities and practical abilities. Finally, they will be assessed according to the completion status of the projects. This kind of project can train and examine students' comprehensive abilities, greatly promote the growth of students, but it is also difficult. In order to achieve teaching effect and train students' teamwork abilities, teachers will require students to form teams to complete projects. In this process, some problems are exposed. For example, some students are afraid and unable to undertake tasks, so there will be uneven assignment of tasks in a team, and even one person supports the whole team. The teaching effect cannot be guaranteed, and the team consciousness is missing. More seriously, some students can not actively face the examination results, and finally give up the majors. All of these problems will affect the learning of subsequent courses and have a huge impact on the sustainable development of the whole industry.

Through the above analysis, we find: students have poor emotional control abilities and psychological quality, and cannot actively transform negative factors. With the accumulation of negative factors, students lose their learning enthusiasm and positive professional emotion. Therefore, the role of teachers is particularly prominent at this time. They should not only keep professional knowledge in mind, have the ability to answer questions, but also pay attention to students' emotions, attach importance to professional emotional education, master the ways and methods of professional emotional education, and guide students to strengthen their professional emotional construction.

\section{THE STRATEGY OF PROFESSIONAL EMOTIONAL EDUCATION}

All teaching have feelings, no feelings of the teaching and learning are short, no matter how much knowledge, or repeated memory of how many times, if there is no emotional investment, these will vanish with time [2].Under the mode of school-enterprise cooperation, school and enterprise should give full play to their respective specialty, deeply integrate and make joint efforts in professional emotional education. This paper proposes the following strategies in professional emotional education.

\section{A. Top-level design}

Zankov Leonid Vladimirovich's development teaching theory said that in order to achieve the personal general development, it is necessary to "stimulate strong and lasting internal incentives to form spiritual strength" [3]. Once the teaching method touches the emotional fields, volitional fields and the spiritual needs of students, it will play a highly effective role [4]. Therefore, in order to ensure the teaching quality, from the formulation of the talent training program to the implementation of teaching methods, we should pay attention to professional emotional education. In addition, it is necessary to build a comprehensive system of professional emotional experience by case teaching, interest groups, competitions and other means to systematically, multi-level and continuously promote the construction of professional emotion. Once such a strong and lasting "internal incentive" is stimulated, students will surely have a great progress in their majors.

School-enterprise cooperation should always promote "people oriented" and "education first". Education is a conscientious profession, when school-enterprise cooperation is carried out, enterprises should abandon the profit-oriented business thesis, put students first and make long-term plans for students. When formulating various teaching policies and implementing documents, school and enterprise should take a long-term view, and even consider the career planning of students within 5-10 years of employment, predict the possible problems in the industry and the development direction in the next few years to ensure the employment persistence of students.

\section{B. Professional quality training}

Professional quality can increase students' cognition and identification about their majors. It is also extremely important for the sustainable development of the whole industry. Therefore, professional quality training should also be put into professional emotional education. Professional quality can't be developed in a short time. Inversely, it needs to be gradually accumulated. Especially for freshmen who don't know about their majors, professional quality education can help them understand the professional background and development prospect. Enterprises can play an important role in the work, because they work at the cutting edge of the industry, and know what the industry needs. For example, enterprise mentors can introduce some excellent enterprises and individuals to increase students' professional pride. In addition to introducing the outstanding achievements of enterprises and individuals, it 
is also necessary to introduce relevant emotional factors such as enterprise culture, social responsibility, national pride and personal quality, to students. The emotional factors can transmit the professional humanistic feelings and emotional colors to students, and then cultivate students' comprehensive quality imperceptibly.

Relative to the imparting of knowledge and skills, education should be more important for the cultivation of independent learning ability and logical thinking ability. Some students find their chosen major is difficult to learn, because they don't grasp its logic rules and feel its beauty and value. Therefore, logical thinking ability training is very necessary and important. With the improvement of logical thinking ability, independent learning ability will also be improved. With the rapid development of computer major, the existing knowledge will be replaced quickly. Only students who have the ability of independent learning can have more sensitive consciousness, get in touch with new things fast, master new skills and avoid being eliminated by the industry.

\section{Respecting individual differences}

Lev Vygot sky found that "even under the classroom teaching system, the proximal development areas of students in the same class are different, with high discreteness" [5]. In other words, under the same teaching environment, individual differences of students will lead to different teaching effects, and the differences are obvious. We should respect the individual differences of students, and adopt different teaching methods according to the individual differences. The tutorial system is invented to meet this need. At present, many colleges and universities have tried this way to provide targeted guidance to students from knowledge to emotion. The teaching should also adopt the multi-evaluation way, which can't only affirm the individual differences of students, but also guide them to develop in the right direction.

\section{Strengthening psychological quality}

The main reason for the lack of professional emotion is that students have poor psychological quality and they cannot actively face setbacks. Therefore, failure education should be added in the professional emotional education. Teachers consciously create difficulties and traps on the basis of the psychological characteristics of students. Through the psychological contrast of failure and success, the professional knowledge of students will be strengthened. Practice shows that the teaching effect of success-failure coupled education is more significant, and students' psychological qualities are also improved.

\section{E. Interest-driven teaching}

Interest is the psychological tendency of people to know about some things or engage in some activities. It is based on the need to know and explore external things and is an important motivation to promote people to know things and explore the truth. The interest occupies the very heavy proportion in the emotion, so it can promote the generation and the consolidation of the professional emotion. Therefore, interest should be taken into account in the course design to mobilize students' interest as much as possible. Outside the classroom, school and enterprise organize students with the same interest together to create interest groups, communities, associations, etc. In teams, students can attack difficulties, share advice, and promote each other. The team as a unit can even participate in some competitions or undertake some projects to improve their skills, teamwork abilities, workplace experience and knowledge. In this process, enterprises should play their own advantages to bring in more updated information, provide technical support and improve students' practical abilities.

At the same time, interest also has instability. Only ensuring the stability, the interest can play a positive role in learning. Therefore, the interest development of students also needs teaching supervision. Both the school and the enterprise should constantly adjust methods and ways to ensure the stability and persistence of students' interests.

\section{F. Others}

- Promoting process assessment. In the traditional teaching mode, teachers just spread knowledge to students, interact with students less. The teaching design is monotonous and boring, and the attraction of classroom is so poor. The traditional test model is that the final grade determines the outcome. The combination of these two traditional modes invisibly leads those students with poor self-control abilities to develop a learning state of "slack at ordinary times and nervous at the end of the semester" [6]. At last, the teaching lacks the continuity and the teaching effect is fall short of expectations. In order to solve such problems, the process assessment should be vigorously promoted, and different teaching methods should be adopted in the teaching process to increase the activity and attractiveness of the classroom. The whole process of classroom teaching should be assessed in stages, and the result of each assessment is counted into the final result of the course. The process assessment will mobilize and make good use of students' nervous emotions, so as to ensure the continuity and effectiveness of the teaching.

- Paying attention to the teaching reflection. With the changes of times and individual students, the teaching system should be updated constantly. The teaching reflection is just an important method which can help modify the educational system. Many colleges and universities have begun to pay attention to teaching reflection, and achieved some results. Next, we should increase the proportion of professional emotional education in teaching reflection. Besides, in order to ensure the teaching quality of enterprises in the whole school-enterprise education system, enterprises should also be assessed, and the assessment should be divided into pre-job assessment and segmented semester assessment. The school should carry out effective communication and supervision over the enterprise, rather than let things drift. If finding any problem in the teaching process, school as the main body of education should timely feedback and make correction. 
- Encouraging innovation. The innovation will drive the development of whole social and have an even greater impact on the computer field. In recent years, machine learning and artificial intelligence have developed rapidly and brought convenience to people in many fields of production and life. And the development of these technologies is undoubtedly inseparable from innovation. Therefore, the computer major should encourage and support students' innovation, no matter how much the innovation is. The innovation will also stimulate professional achievement and identity.

\section{CONCLUSION}

Professional emotion will provide students with a stable and strong professional centripetal force, ensure the persistence of employment, and promote the sustainable development of the industry. Education is subtle and gradual, so professional emotional education should also be slowly infiltrated. Professional emotional education should not be implemented from an aspect, also can't complete in a short time. Now, what we can do and what we need to do are a lot. School and enterprise should work hard from all aspects. Both sides should always be student-oriented, deeply integrate and work together in the professional emotional education.

\section{ACKNOWLEDGMENT}

Taishan University gave financial support to the project. I would like to take this opportunity to extend my sincere gratitude to Taishan University. In the process of the writing, the leaders and colleagues of information science and technology, Taishan University gave my help and guidance. I feel deeply grateful and fortunate to get acquainted with you.

\section{REFERENCES}

[1] Beibei Jin, "Analysis on the significance and approach of higher vocational students' professional emotion training", SHANGYE JINGJI, no.9, 2007, pp.114-115. (In Chinese)

[2] Li Nian, Fei Wang,"On the importance of emotional cultivation in vocal music teaching", in International Journal of Technology Management, no.6, 2017, pp. 13-15.

[3] Yunsheng Liu, "Research on teaching sustainable development based on Zankov Leonid Vladimirovich's teaching and development theory", Foreign Education Research, no.5, 1999, pp.6-10. (In Chinese)

[4] Zankov Leonid Vladimirovich, Teaching and Development, People's education press, 2008.

[5] Changchun Wang, Yuhua Ye, "Criticism on Russian developmental teaching theory", Comparative Education Research, no.1, 2001. (In Chinese)

[6] Zhongmei Sun, Ye Chen, Keng Lin, "Innovation and practice of undergraduate teaching reform based on "process assessment" -- a case study of Shenzhen university", Journal of Heilongjiang College of Education, no.11, 2012, pp.53-55.(In Chinese) 